\title{
KORELASI DUKUNGAN SOSIAL DENGAN KESEHATAN JIWA SANTRI PUTRA DI PONDOK PESANTREN LUMAJANG
}

\author{
Dian Pitaloka Priasmoro \\ Institut Teknologi Sains dan Kesehatan RS dr. Soepraoen Malang \\ E-mail: priasmoro.pitaloka@gmail.com
}

\begin{abstract}
Indonesia have various form of schools both regular and pesantren-based. The student of pesantren or Islamic Boarding School lack of time to be able to gather with family and home environment and cause problems in the mental health of the students. This study aims to analyze the relationship of social support with the mental health of students in Islamic Boarding School conducted in May 2020. The design used in this study is observasional (cross sectional), the population is all male students in F block totaling 50 people, the sample is part students totally 42 people. The sampling technique used was simple random sampling, the instruments used were social support questionnaire and Mental Health Inventory. Data collected by sharing the google form link, then the data was coding, editing, tabulating and analyzed univariate by percentage and bivariate by the Sommers'd test. The results showed that social support of large students in the medium category was 30 people $(71.4 \%)$, mental health of almost all students had mental health with a prosperous enough life of 36 people (85.7\%), and there was a fairly strong relationship between social support with mental health with a value of co-eficient correlation 0.434 and p-value 0.007 which is possible due to various factors such as the age of the student, length of stay in boarding school, support from friends or parents. Based on the results of the study it is suggested that teacher at Islamic boarding school must conduct communication activities more often so that students can talk about problems they are facing and not feel alone.
\end{abstract}

Keywords: Social support; mental health.

\begin{abstract}
ABSTRAK
Indonesia memiliki beragam bentuk sekolah baik berbasis reguler maupun pesantren. Para santri di pesantren seringkali mengalami kekurangan waktu untuk bisa berkumpul dengan keluarga dan merasakan lingkungan rumah. Sehingga dapat menimbulkan gangguan pada kesehatan jiwa santri. Penelitian ini bertujuan untuk menganalisis hubungan dukungan sosial dengan kesehatan jiwa santri di Pondok Pesantren yang dilaksanakan pada bulan Mei 2020. Desain yang digunakan dalam penelitian ini adalah observasional (cross sectional), populasinya adalah seluruh santri putra di blok $\mathrm{F}$ yang berjumlah 50 orang, sampel adalah sebagian santri berjumlah 42 orang. Teknik pengambilan sampel yang digunakan adalah simple random sampling, instrumen yang digunakan adalah angket dukungan sosial dan Mental Health Inventory. Pengumpulan data dilakukan dengan membagikan link google form, kemudian

Cara mengutip: Priasmoro, D. Pitaloka. (2020). Korelasi Dukungan Sosial dengan Kesehatan Jiwa Santri Putra di Pondok Pesantren Lumajang. Care:Jurnal Ilmiah Ilmu Kesehatan, 8(3), 424-434
\end{abstract}


data dikode, diedit, ditabulasi dan dianalisis secara univariat berdasarkan persentase dan bivariat dengan tes Sommers'd. Hasil penelitian menunjukkan bahwa dukungan sosial santri sebagian besar pada kategori sedang sebanyak 30 orang $(71,4 \%)$, kesehatan jiwa santri hampir seluruhnya cukup sejahtera sebanyak 36 orang $(85,7 \%)$, dan terdapat hubungan yang cukup kuat antara dukungan sosial dengan kesehatan jiwa dengan nilai koefisien korelasi 0,434 dan p-value 0,007 yang dimungkinkan karena berbagai faktor seperti usia santri, lama tinggal di pondok pesantren, dukungan dari teman atau orang tua. Berdasarkan hasil penelitian disarankan agar guru di pesantren lebih sering melakukan kegiatan komunikasi agar santri dapat berbicara tentang masalah yang mereka hadapi dan tidak merasa sendirian.

Kata Kunci: Dukungan sosial; kesehatan mental.

\section{PENDAHULUAN}

Di Indonesia kita mengenal berbagai macam bentuk sekolah baik reguler maupun berbasis pesantren. Bashori (2017) menyebutkan bahwa pesantren merupakan lembaga pendidikan Islam yang memiliki akar historis yang cukup kuat sehingga menduduki posisi relatif sentral dalam dunia keilmuan. Pesantren adalah lembaga pendidikan keagamaan Islam berbasis masyarakat yang menyelenggarakan pendidikan diniyah (tradisional) atau secara terpadu dengan jenis pendidikan lainnya, seperti pendidikan formal (modern). Pada masamasa mendatang pilihan masuk ke pesantren sangat dibutuhkan dengan tujuan untuk menyeimbangakan akal dan hati (Tafsir, 2011). Menurut data Kementrian Agama republik Indonesia tahun 2017 disebutkan data statistik bahwa jumlah penyelenggara pendidikan diniyah dan pesantren di setiap Provinsi menduduki lebih dari 50\%. Hasil penelitian Hidayat (2018) didapatkan hasil dari 40 santri di PP Ma'had AlMuqoddasah Litahfidzil Qur'an sebagian besar santri mengalami permasalahan yang sering dirasakan ketika dipesantren karena hambatan penyesuaian diri, sulit berkomunikasi dengan teman, maupun dengan lingkungan tempat tinggal.

Para pelajar pesantren disebut sebagai santri yang belajar pada sekolah ini, sekaligus tinggal pada asrama yang disediakan oleh pesantren. Minimnya waktu untuk bisa berkumpul dengan keluarga maupun lingkungan rumah seringkali menimbulkan permasalahan kepada para santri seperti sedih, merasa sendiri, dan menimbulkan permasalahan dalam kesehatan jiwa para santri (Samranah, 2017).

Kesehatan jiwa dipengaruhi oleh berbagai faktor antara lain otonomi dan kemandirian, memaksimalkan potensi diri, mentoleransi ketidakpastian hidup, harga 
diri, menguasai lingkungan, orientasi realitas serta manajemen stress. Faktor faktor tersebut berinteraksi secara tetap sehingga kesehatan jiwa seseorang merupakan keadaan dinamik atau selalu berubah karena dipengaruhi pula oleh lingkungan, pengalaman seseorang dalam menghadapi masalah, mekanisme koping serta dukungan sosial (Handono et al., 2013). Dukungan sosial adalah tersedianya orang lain atau kelompok yang memberikan rasa nyaman, perhatian, dan penghargaan ataupun menawarkan bantuan terhadap individu. Dukungan ini berasal dari berbagai sumber, yaitu pasangan, keluarga, teman, tetangga, dsb (Sari, dkk, 2016). Menurut Harandi, dkk (2017) juga telah disebutkan bahwa dukungan sosial merupakan faktor yang sangat penting yang dapat mempengaruhi kesehatan mental. Dukungan sosial memberikan keuntungan baik secara fisik maupun psikologis bagi seseorang untuk menghadapi stressor dalam kehidupan sehari-hari. Menurut Hsieh\&Tsai (2019) menyebutkan bahwa faktor internal (harga diri, dan penerimaan diri) dan faktor eksternal (dukungan sosial) dapat membantu seseorang dalam berkompromi dengan tekanan hidup. Hal ini menunjukkan bahwa dukungan sosial merupakan faktor penting dalam menyeimbangkan dampak negatif dari tekanan hidup baik secara fisik maupun psikologis.

\section{METODE PENELITIAN}

Desain yang digunakan dalam penelitian ini adalah observasional (cross sectional). Populasi adalah seluruh santri putra di blok F sejumlah 50 orang, sampel adalah sebagian santri sejumlah 42. Teknik sampling yang digunakan adalah simple random sampling. Instrumen yang digunakan adalah kuisioner dukungan sosial dan Mental Health Inventory dari The Consortium of Multiple Sclerosis Centers Helath Services Research Subcommittee tahun 1997. Pengumpulan data dilakukan dengan membagikan tautan google form. Analisis data yang digunakan univariat dengan persentase dan bivariat dengan uji Sommers'd.

\section{HASIL}

Berdasarkan Tabel 1 diketahui bahwa sebagian besar responden berusia 19-21 tahun, lebih dari separuhnya tinggal di pesantren $>5$ tahun, hampir seluruhnya pendapatan orang tua $<1$ juta, hampir seluruhnya tingal di asrama karena keinginan pribadi, hampir seluruhnya mengalami fase adpatasi, hampir seluruhnya sering bercerita dengan teman, dan lebih dari separuh merasa sering dibantu oleh teman. 
Tabel 1. Data Umum Responden

\begin{tabular}{|c|c|c|}
\hline Variabel & f & $(\%)$ \\
\hline \multicolumn{3}{|l|}{ Umur responden } \\
\hline 13-15 tahun & 5 & 11,9 \\
\hline 16-18 tahun & 15 & 35,7 \\
\hline 19-21 tahun & 22 & 52,4 \\
\hline Sub Total & 42 & 100 \\
\hline Lama di pesantren & $\mathrm{f}$ & $\%$ \\
\hline $0-1$ th & 4 & 9,5 \\
\hline $2-5$ th & 14 & 33,3 \\
\hline$>5$ th & 24 & 57,1 \\
\hline Sub Total & 42 & 100 \\
\hline \multicolumn{3}{|l|}{ Pendapatan orang tua } \\
\hline$<1$ juta & 31 & 73,8 \\
\hline $1-3$ juta & 6 & 14,3 \\
\hline$>3$ juta & 5 & 11,9 \\
\hline Sub Total & 42 & 100 \\
\hline $\begin{array}{l}\text { Apakah sekolah di } \\
\text { pesantren }\end{array}$ & & \\
\hline \multicolumn{3}{|l|}{ Pribadi } \\
\hline $\mathrm{Ya}$ & 40 & 95,2 \\
\hline Tidak & 2 & 4,8 \\
\hline Sub Total & 42 & 100 \\
\hline \multicolumn{3}{|l|}{ Responden mengalami } \\
\hline \multicolumn{3}{|l|}{ Fase Adaptasi } \\
\hline $\mathrm{Ya}$ & 37 & 88,1 \\
\hline Tidak & 5 & 11,9 \\
\hline Sub Total & 42 & 100 \\
\hline \multicolumn{3}{|l|}{$\begin{array}{l}\text { Siapa orang yang } \\
\text { sering diajak cerita }\end{array}$} \\
\hline Orang tua & 3 & 7,1 \\
\hline Teman & 38 & 90,5 \\
\hline Pengurus Pondok & 1 & 2,4 \\
\hline Sub Total & 42 & 100 \\
\hline \multicolumn{3}{|l|}{$\begin{array}{l}\text { Siapa orang yang } \\
\text { banyak membantu }\end{array}$} \\
\hline Orang tua & 14 & 33,3 \\
\hline Teman & 26 & 61,9 \\
\hline Saudara/Wali & 1 & 2,4 \\
\hline Pengurus Pondok & 1 & 2,4 \\
\hline Sub Total & 42 & 100 \\
\hline
\end{tabular}

Berdasarkan Tabel 2 diketahui sebagian besar responden memiliki dukungan sosial dalam kategori sedang sebanyak 30 orang $(71,4 \%)$.

Tabel 2. Dukungan Sosial Santri

\begin{tabular}{ccc}
\hline Kategori & $\mathbf{f}$ & $\mathbf{( \% )}$ \\
\hline Rendah & 4 & 9,5 \\
Sedang & 30 & 71,4 \\
Tinggi & 8 & 19 \\
Sub total & $\mathbf{4 2}$ & $\mathbf{1 0 0}$ \\
\hline
\end{tabular}

Berdasarkan Tabel 3 diketahui bahwa kesehatan jiwa santri sebagian besar cukup sejahtera sebanyak 36 orang $(85,7 \%)$.

Tabel 3. Kesehatan Jiwa Santri

\begin{tabular}{lcc}
\hline \multicolumn{1}{c}{ Kategori } & f & $\mathbf{( \% )}$ \\
\hline Kurang Sejahtera & 2 & 4,8 \\
Cukup Sejahtera & 36 & 85,7 \\
Sejahtera & 4 & 9,5 \\
Sub total & $\mathbf{4 2}$ & $\mathbf{1 0 0}$ \\
\hline
\end{tabular}

Berdasarkan Tabel 4 diketahui bahwa dari hasi uji Sommers'd didapatkan koefisien korelasi 0.434 yang menunjukkan korelasinya cukup kuat dan nilai p-value $0.007<0.05$ yang artinya terdapat hubungan antara social support dengan kesehatan jiwa.

Tabel 4. Hubungan Dukungan Sosial Dengan Kesehatan Jiwa

\begin{tabular}{lcccc}
\hline Social Support & \multicolumn{3}{c}{ Kesehatan Jiwa } & Total \\
& Kurang sejahtera & Cukup sejahtera & Sejahtera & \\
\hline Rendah & $1(2,4 \%)$ & $3(7,2 \%)$ & 0 & $4(9,6 \%)$ \\
Sedang & $1(2,4 \%)$ & $29(68,8 \%)$ & 0 & $30(71,2 \%)$ \\
Tinggi & 0 & $4(9,6 \%)$ & $4(9,6 \%)$ & $8(19,2 \%)$ \\
Total & $2(4,8 \%)$ & $36(85,6 \%)$ & $4(9,6 \%)$ & $42(100 \%)$ \\
\hline
\end{tabular}

Tabel 5. Analisa Hubungan Dukungan Sosial dengan Kesehatan Jiwa

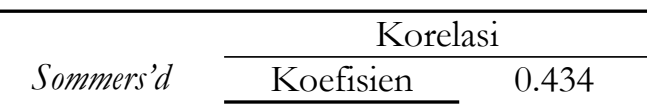




\begin{tabular}{cc}
\hline $\begin{array}{c}\text { Korelasi } \\
\text { p-value }\end{array}$ & 0.007 \\
\hline
\end{tabular}

Berdasarkan Tabel 5 diketahui bahwa dari hasi uji Sommers'd didapatkan koefisien korelasi 0.434 yang menunjukkan korelasinya cukup kuat dan nilai p-value $0.007<0.05$ yang artinya terdapat hubungan antara dukungan sosial dengan kesehatan jiwa.

\section{PEMBAHASAN}

\section{Gambaran Dukungan Sosial Santri}

Berdasarkan tabel 2 diketahui bahwa lebih dari setengah responden memiliki dukungan sosial dengan kategori sedang dan sebagian kecil dalam kategori rendah. Handono et al., (2013) menjelaskan bahwa dukungan sosial adalah hubungan yang sifatnya menolong disaat individu sedang mengalami persoalan atau kesulitan baik berupa informasi maupun bantuan nyata. Dukungan sosial ini dapat diperoleh dari teman, keluarga atau orang yang ada disekitar individu. Dari hasil penelitian diketahui pada tabel 1 bahwa lebih dari setengah responden merasa diberikan dukungan oleh teman. Hal ini diasumsikan bahwa responden memiliki dukungan sosial sedang karena memiliki teman selama di pesantren yang hadir secara nyata ketika santri membutuhkan pertolongan maupun bantuan selama tinggal dipesantren.
Kehidupan dipesantren sebagai sebuah lembaga tempat berprosesnya budaya dan agama Islam yang berada di tengah lingkungan masyarakat mau tidak mau menuntut para santri yang tinggal didalamnya untuk mematuhi aturan. Termasuk dalam komunikasi antar anggotanya seperti para kiai, ustadz, dan santri sudah barang tentu model komunikasi yang diaplikasikan berbeda (Hartono, 2016). Berdasarkan teori diatas diasumsikan oleh peneliti bahwa para santri akan merasa lebih nyaman dan terbuka ketika berkomunikasi untuk mendapatkan dukungan sosial ketika memerlukan bantuan.

Dari tabel 1 juga diketahui bahwa hampir setengah responden mengungkapkan diberikan dukungan oleh orang tua. Hasil penelitian tersebut dapat diasumsikan bahwa santri juga merasa bahwa ada orang tua yang dapat membantu kapanpun dibutuhkan meskipun tidak dapat hadir secara fisik untuk membantu santri karena aturan di pesantren terkait waktu kunjungan oleh orang tua. Meskipun orang tua tidak dapat hadir setiap saat namun kesediaan orang tua ini yang membuat para santri merasa diperhatikan dan dicintai. Asumsi peneliti sejalan dengan teori (Siska et al., 2018) 
yang menyebutkan bahwa dukungan yang diberikan orang tua kepada anak akan membuat anak lebih semangat. Dukungan sosial yang diberikan orang tua merupakan dukungan yang paling besar dalam lingkungan keluarga. Orang tua merupakan bagian dalam keluarga yang dianggap sebagai seorang individu dewasa yang perannya sangat penting karena paling dekat dengan anak. Dukungan sosial adalah hubungan interpersonal antara seseorang dengan orang lain yang didalamnya berisi pemberian bantuan yang melibatkan aspek-aspek yang terdiri dari emosional, penghargaan, instrumental, dan informasi. Dukungan emosional misalnya adalah kehadiran seseorang untuk diajak berbagi atau bercerita (Siska et al., 2018). Dari hasil penelitian pada tabel 1 diketahui bahwa sebagian besar santri dengan dukungan sosial sedang sering bercerita kepada teman. Pernyataan diatas dapat diasumsikan bahwa santri yang memiliki dukungan sosial sedang dikarenakan memiliki seseorang yaitu teman untuk mendengarkan keluh kesah atau masalaah yang dihadapi meskipun tidak semua santri mengungkapkan masalah atau bercerita kepada teman.

Sedangkan dukungan instrumental contohnya adalah pemberian dukungan dalam bentuk sarana prasarana maupun pembiayaan bagi santri. Dari hasil penelitian pada tabel 1 diketahui bahwa sebagian besar orang tua santri ayahnya bekerja sebagai petani, lebih dari setengah responden memiliki ibu tidak bekerja/ IRT, dan sebagian besar pendapatan orang tua $<1$ juta. Hasil penelitian ini diasumsikan bahwa santri yang memiliki dukungan sosial sedang dimungkinkan karena sebagian besar orang tua responden bekerja sebagai petani maupun tidak bekerja, sehingga memiliki pendapatan yang relatif rendah yaitu kurang dari 1 juta. Kondisi ini menyebabkan orang tua tidak bisa secara maksimal memberikan dukungan secara materiil. Asumsi peneliti ini sejalan dengan Siska et al., (2018) yang menyatakan bahwa dukungan yang diberikan orang tua kepada anak salah satunya adalah menyediakan fasilitas yang diperlukan anak untuk belajar. Fasilitas tersebut berupa penyediaan alat tulis, buku pelajaran, maupun fasilitas yang lainnya.

\section{Gambaran Kesehatan Jiwa Santri}

Berdasarkan tabel 3 diatas diketahui bahwa hampir seluruh responden responden memiliki kesehatan jiwa cukup sejahtera, dan sebagian kecil kurang sejahtera. Kesehatan jiwa merupakan kondisi seorang individu yang sejahtera. 
Dimana individu mencapai kebahagiaan, ketenangan, kepuasan, aktualisasi diri, dan mampu optimis atau berfikir positif di segala situasi baik terhadap diri sendiri, orang lain, dan lingkungan (Wuryaningsih, 2018). Sedangkan menurut Indarjo (2009) disebutkan pada masa remaja, banyak terjadi perubahan biologis, psikologis maupun sosial. Tetapi umumnya proses pematangan fisik terjadi lebih cepat dari proses pematangan kejiwaan (psikososial). Manusia selalu dilihat sebagai satu kesatuan utuh dari unsur badan, jiwa, sosial, tidak hanya dititik beratkan pada penyakit tetapi pada peningkatan kualitas hidup, terdiri dari kesejahteraan dari badan, jiwa dan produktivitas secara sosial ekonomi.

Adanya konflik yang berlarut-larut dapat menjadi stresor bagi remaja yang dapat menimbulkan berbagai pemasalahan yang komplek baik fisik, psikologik maupun sosial termasuk pendidikan. Kondisi seperti ini apabila tidak segera di atasi dapat berlanjut sampai dewasa dan dapat berkembang ke arah yang lebih negatif. Antara lain dapat ditimbulkan masalah maupun gangguan kejiwaan dari yang ringan sampai berat (Indarjo, 2009).

Menurut hasil penelitian pada tabel 1 diketahui bahwa sebagian besar responden berumur 19-21 tahun dan sebagian kecil berumur 13-15 tahun . Dari beberapa pernyataan teori diatas dan hasil penelitian dapat diasumsikan oleh peneliti bahwa santri dengan kesehatan jiwa yang cukup sejahtera dimungkinkan karena memiliki umur yang cukup matang yaitu 19-21 tahun atau dewasa muda. Dimana pada usia ini individu dianggap sudah mampu berfikir secara matang terhadap segala permasalahan yang dihadapi dan lebih banyak kearah mencari solusi. Sehingga seseorang tidak akan mudah menganggap suatu masalah yang dihadapi sebagai suatu stressor yang berat dan menimbulkan masalah pada kesehatan jiwa. Asumsi peneliti ini sejalan dengan teori Kelen, Agnesia Priska L.; Hallis, Farida, Puri, (2016) yang menyebutkan bahwa semakin matang umur individu maka akan semakin menjadikannya lebih dewasa dan matang dalam bertindak dan bersikap. Yusuf, (2009) menjelaskan bahwa semakin cukup umur tingkat kematangan dan kekuatan seseorang, maka akan lebih matang seseorang tersebut dalam berfikir dan berkarya.

Kesehatan jiwa juga merupakan kemampuan individu dalam menerima perubahan yang dialami baik fisik, mental, sosial maupun lingkungannya (Indarjo, 2009). Berdasarkan hasil penelitian diketahui bahwa hampir seluruh 
ressponden mengalami dengan kesejahteraan cukup mengalami fase adaptasi. Hal ini diasumsikan peneliti bahwa responden yang memiliki kesehatan jiwa cukup dikarenakan mereka mampu menghadapi perubahan yang terjadi melalui proses penyesuaian diri.

Dari tabel 1 juga didapatkan hasil penelitian lebih dari setengah responden tinggal di pesantren $>5$ tahun, dan sebagian besar 2-5 tahun. Berdasarkan hasil penelitian tersebut diasumsikan penelitia bahwa waktu lima tahun merupakan waktu yang sangat panjang bagi seorang santri untuk belajar, mengenali dan menerima lingkungan sekitarnya. Sehingga santri dapat menerima perubahan lingkungan atau situasi. Hal tersebut membuat santri lebih mudah menerima permasalahan yang muncul akibat lingkungannya dan tidak dianggap stressor sehingga kesehatan jiwa nya cukup sejahtera.

Asumsi peneliti ini sejalan dengan teori (Kirana, 2013) yang menyebutkan bahwa culture shock dapat dialami oleh siapa saja yang setelah sekian lama tinggal di suatu tempat kemudian karena suatu hal dia pindah ke tempat lain yang memiliki budaya berbeda. Untuk dapat bertahan dalam lingkungannya yang baru, setiap individu pasti akan melakukan suatu adaptasi maka seseorang tentu juga akan berusaha melakukan adaptasi atau penyesuaian diri terhadap budaya di lingkungan baru mereka. Untuk dapat beradaptasi dilingkungan yang baru setidaknya seseorang membutuhkan waktu antara 8-12 bulan.

\section{Hubungan Dukungan Sosial dengan} kesehatan Jiwa.

Berdasarkan tabel 4 diatas diketahui bahwa dari hasi uji Sommers'd didapatkan koefisien korelasi 0.434 yang menunjukkan korelasinya cukup kuat dan nilai p-value $0.007<0.05$ yang artinya terdapat hubungan antara social support dengan kesehatan jiwa. Dari hasil penelitian tersebut diasumsikan peneliti bahwa ada hubungan antara social support dengan kesehatan jiwa dengan korelasi yang cukup kuat. Asumsi peneliti ini sejalan dengan Siska et al., (2018) yang menyebutkan bahwa seorang anak yang berada dalam keluarga memperoleh dukungan sosial dari orang tua yang kuat akan menjadi individu yang lebih optimis dalam menghadapi kehidupan saat ini maupun akan datang.

Individu akan lebih terampil dalam memenuhi kebutuhan psikologis, mempertinggi soft skill, dan memiliki 
kemampuan untuk mencapai apa yang diinginkan. Kemampuan untuk memenuhi kebutuhan psikologis atau beradaptasi ini yang akhirnya membuat individu memiliki kesehatan jiwa yang sejahtera (Yusuf, Ahmad; Nihayati, Hanik; dkk. 2019). Dukungan sosial ini tidak hanya didapatkan dari orang tua namun bisa saja dari teman, keluarga maupun orang terdekat (Siska et al., 2018).

Berdasarkan tabel 4 diketahui bahwa lebih dari setengah responden dengan dukungan sosial yang sedang memiliki kesehatan jiwa yang cukup sejahtera. Hasil penelitian ini sejalan dengan teori (Bukhori, 2012) yang menyebutkan bahwa dukungan sosial keluarga merupakan variabel lingkungan yang diasumsikan memiliki hubungan positif dengan kesehatan jiwa seseorang. Dukungan tersebut diharapkan berasal dari keluarga karena keluarga merupakan lingkungan pertama dan lingkungan yang terdekat dengan individu (Apollo dan Cahyadi, 2012). Berdasarkan pernyataan diatas diasumsikan bahwa para santri merasa memiliki orang terdekat seperti keluarga yaitu orang tua maupun teman yang dianggap seperti keluarga karena paling dekat dengan santri dan berada disekitar santri. Dukungan sosial dari teman maupun orang tua ini diperlukan untuk menghilangkan rasa ketakutan atau kecemasan dan masalah-masalah yang muncul selama santri tinggal dipesantren dan jauh dari orang tua. Perasaan memiliki, berharga, dan dicintai ini akan memberikan semangat tersendiri bagi santri untuk menerima keadaan atau beban yang dialami sehingga kesehatan jiwa santri akan menjadi cukup sejahtera. Dan sebaliknya pada santri yang mendapatkan social support rendah memiliki kesehatan jiwa kurang sejahtera.

\section{KESIMPULAN}

Dukungan sosial santri di Pondok Pesantren Miftahul Ulum sebagian besar dalam kategori sedang, dan sebagian kecil rendah. Hal ini dimungkinkan dipengaruhi oleh adanya orang yang sering diajak bercerita, santri mendapatkan dukungan dari orang tua atau teman, pekerjaan orang tua, dan pendapatan orang tua. Kesehatan jiwa santri di Pondok Pesantren Miftahul Ulum hampir seluruh responden responden memiliki kesehatan jiwa dengan cukup sejahtera, dan sebagian kecil kurang sejahtera. Hal ini dimungkinkan karena umur, mengalami fase adaptasi, dan lama tinggal diasrama. Terdapat hubungan dukungan sosial dengan ksehatan jiwa santri di Pondok Pesantren Miftahul Ulum terdapat 
hubungan dengan nilai p-value $0.007<$ 0.05 dan kekuatan hubungan yang cukup kuat sebesar 0.434 .

\section{UCAPAN TERIMA KASIH}

Rektor Institut Teknologi, Sains, dan kesehatan RS dr.Soepraoen Malang yang telah memberikan kebijakan pendanaan hibah penelitian internal dosen dan seluruh responden yang telah berpartisipasi dalam penelitian ini.

\section{REFERENSI}

Apollo dan Cahyadi. (2012). Konflik Peran Ganda Perempuan Menikah yang Bekerja Ditinjau dari Dukungan Sosial Keluarga dan Penyesuaian Diri. Jurnal Widya W arta No.02 Vol.0854-1981.

Bashori. (2017). Modernisasi lembaga pendidikan pesantren. Jurnal Ilmu Sosial Mamangan. Volume 6 Nomor 1, Januari-Juni 2017.

Bukhori, B. (2012). Hubungan Kebermaknaan Hidup Dan Dukungan Sosial Keluarga Dengan Kesehatan Mental Narapidana (Studi Kasus Narapidana Kota Semarang). Jurnal Ad-Din, 4(1).

Handono, O. T., Psikologi, F., Ahmad, U., \& Yogyakarta, D. (2013). Hubungan Antara Penyesuaian Diri Dan Dukungan Sosial Terhadap Stress Lingkungan Pada Santri Baru. Empathy Jurnal Fakultas Psikologi, 1(2), 79-89.

Hartono, R. (2016). Pola Komunikasi di Pesantren: Studi tentang Model Komunikasi antara Kiai, Ustadz, dan Santri di Pondok Pesantren TMI Al-Amien Prenduan. AlBalagh: Jurnal Dakwah Dan Komunikasi, $\quad 1(1), \quad 67$. https://doi.org/10.22515/balagh.v $1 \mathrm{i} 1.60$

Harandi, Tayebeh Fasihi, et all. (2017). The corelation of social support with mental health: a meta-analysis. Electronic physician. Volume (9). Issue 9. September 2017.

Hidayat, Rizal L. (2018). Skripsi:Hubungan Penyesuaian Diri Terbadap Stress Lingkungan Pada Santri Baru Di Pondok Pesantren Ma'had AlMuqoddasah Litabfidril Qur'an Ponorogo. Malang:Universitas Islam Negeri.

Hsieh, Ching-Ming; Tsai, Bi-Kun. (2019). Effects of social support on the stress-health relationship: gender comparison among military personnel. International Journal of Environmental research and public health. Vol.16. 12 April 2019.

Indarjo, S. (2009). Kesehatan Jiwa Remaja. KEMAS: Jurnal Kesehatan Masyarakat, 5(1), 48-57.

Kelen, Agnesia Priska L.; Hallis, Farida, Puri, R. M. (2016). Tugas Keluarga Dalam Pemeliharaan Kesehatan Dengan Mekanisme Koping Lansia. Jurnal Care, 4(1), 58-65.

Kirana, R. P. (2013). Strategi Adaptasi Pekerja Jepang Terhadap Culture Shock Studi Kasus Terhadap Pekerja Jepang di Instansi Pemerintah di surabaya. Japanology, 1(1), 1-11.

Samranah. (2017). Skripsi: Faktor-Faktor Yang Mempengaruhi Status Kesehatan Pada Santri Kelas X Sma Di Pondok Pesantren Ummul Mukminin Makassar. Fakultas Kedokteran Dan Ilmu Kesehatan Uin Alauddin: Makassar.

Sari, Syarifah M; Lestari, Intan Y; Yulianti, Alma. (2016). Hubungan antara social support dan self-eficacy dengan stress pada ibu rumah tangga yang berpendidikan tinggi. Psympathic Jurnal Ilmiah Psikologi.Vol.3. No.2.hal 171-178. 
Siska, M., Solfema, S., \& Aini, W. (2018). Hubungan Dukungan Sosial Orang Tua dengan Hasil Belajar Santri di MDA Nurul Haq Nagari Cubadak Kecamatan Dua Koto Kabupaten Pasaman. Spektrum: Jurnal Pendidikan Luar Sekolah (PLS), 1(2), 238. https://doi.org/10.24036/spektru mpls.v1i2.9053

Tafsir, A. (2011). Pendidikan Dalam Prespektif Islam. Bandung: Remaja Rosdakarya.
Wuryaningsih, E. W. dkk. (2018). Keperawatan Kesehatan Jiwa 1. UPT Percetakan \& Penerbitan Universitas Jember.

Yusuf, S.(2009). Psikologi Perkembangan Anak dan Remaja. Bandung: PT Remaja.

Yusuf, Ahmad; Nihayati, Hanik; dkk. (2019). Kesehatan Jiwa: Pendekatan Holistik dalam Asuhan Keperawatan. Jakarta: Mitra Wacana Media. 